\title{
Major Currency Pairs: Forex Market
}

\author{
Ritu Kothiwal, Abinaya Rajiyan
}

\begin{abstract}
To analyze the Foreign exchange market on needs to use fundamental, technical and sentimental analysis. This paper majorly focuses on technical analysis the study of charts patterns from the past data. The paper focused on the trends of the FOREX Market to predict the future price by past actions and also to determine the factors influencing the drastic changes. The paper analyzes the most highly traded currency at which time as well as the profit and loss ratio in FOREX Market trading. The analysis of currency pairs takes in view of 3 points:

- Price takes into account everything

- The price is a subject to a trend

- History repeats itself.
\end{abstract}

Keywords : Technical analysis, Fundamental analysis, Sentimental analysis, interest rate and inflation rate.

\section{INTRODUCTION}

$\mathrm{F}_{\text {orex market is an OTC market where traders don't have }}$ to be present physically everything is done using online platforms. The Forex market is like a wholesale segment where the dealing directly takes place between the customers and banks. The basis of Forex market is trading one country's currency pairs towards other currencies. The world's largest market, Forex growing swiftly and day trades is $\$ 5$ million.

The exchange rate is determined by comparison between two currencies where major currencies traded are the Euro (EUR), Japanese Yen (JPY), British Pound (GBP) United States Dollar (USD) and the Swiss Franc (CHF). Commonly traded, major currency pairs are

\section{- EUR/USD \\ - GBP/USD \\ - USD/JPY \\ - USD/CHF}

In a currency pair, first currency known as BASE CURRENCY; second currency known as QUOTE CURRENCY. The base currency is bought and the quote currency is sold, while buying the currency pair. Visa-Versa, the base currency is sold and the quote currency is bought while selling the currency pair. In order to carry out the analysis of Forex market, number of tools/indicators are used to determine whether given currency pair to be buy or sell such as candle stick pattern, Relative strength index, Bollinger band, Moving average.

Revised Manuscript Received on December 05, 2019.

* Correspondence Author

Dr. Ritu Kothiwal*, Associate Professor, VVISM, Hyderabad, India.

Dr. Abinaya Rajiyan, PGDM, VVISM, Hyderabad, India.
Trading Rule of Forex, SELL at HIGH and BUY at LOW where trading is of one currency against the other currency. It's not so easy to consider either low or high, in advance. Though, if influencing factors of currency rate is known, predictions can be feasible. Spread Currency is an important factor, means difference between the buying rate and the selling rate of the currency. Considering spread factor, trader need to analyze the market and trade.

\section{OBJECTIVE OF THE STUDY}

- To learn on international currencies with virtual money.

- To determine the factors influencing the drastic changes

- To determine which currency pairs has more/less volatility

\section{RESEARCH METHODOLOGY}

To understand the changes in FOREX Market trends by using candlestick charts and statistical indicators like Relative strength index, Bollinger bands, stochastic indicator and moving averages are used. The historical data is collected from Meta Trader 4 trading platform from 5-06-2019 to 5-07-2019.

\section{ANALYSIS}

Currencies are traded in the 3 categories of time

1. Hourly

2. Midday

3. Daily.

\section{Timing Range and Duration:}

1. Less than 12 hours between opening and closing position, traded category is hourly.

2. Between 12 and 24 hours, category placed in midday

3. More than 24 hours, category belongs to daily.

No Manual closure, automatically terminated by hitting the stop loss or profit as performed on the trading platform. Moreover, in each position 40 pips are determined for taking profit and stop loss where positions are taken by signals using indicators, tools and patterns.

Published By:

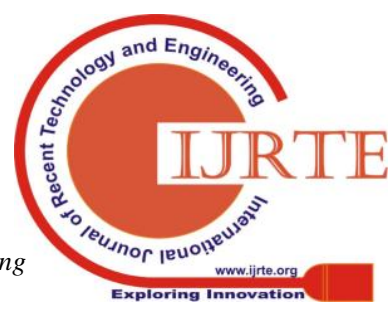




\section{A. Stochastic Oscillator}

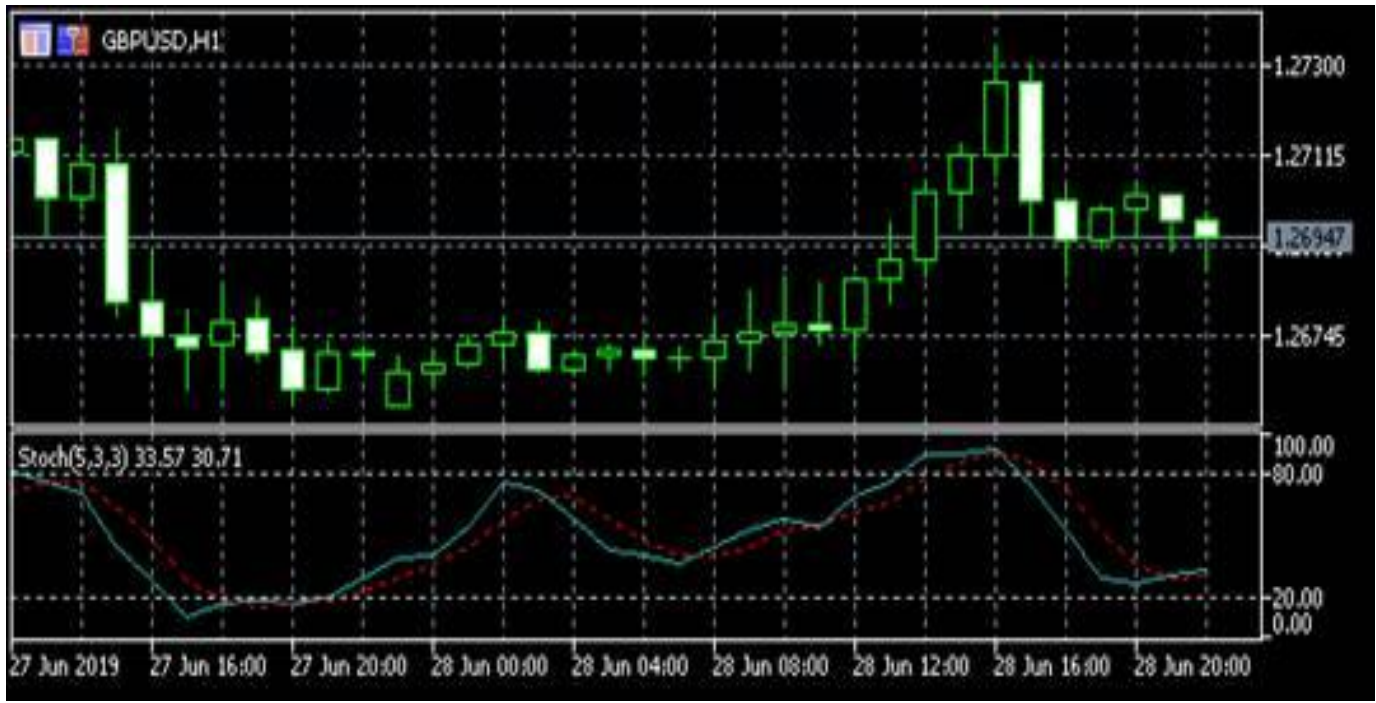

Figure - 1: A.Stochastic Oscillator

- The oscillator follows the speed or momentum of price

- The stochastic oscillator can play an important role in identifying over brought and oversold levels.

- In this, it can be seen that there are two lines, red and blue the blue line is for the buyers and red line is for the sellers. When blue line is above red line then, it is said that the market is strong for buyers as compare to sellers.

One of the methods of using the stochastic oscillator, to look for overbought areas (above 80) as well as oversold areas (below 20). Above chart shows stochastic oscillator below 20 which is an oversold reading.

\section{B. Relative Strength Index}

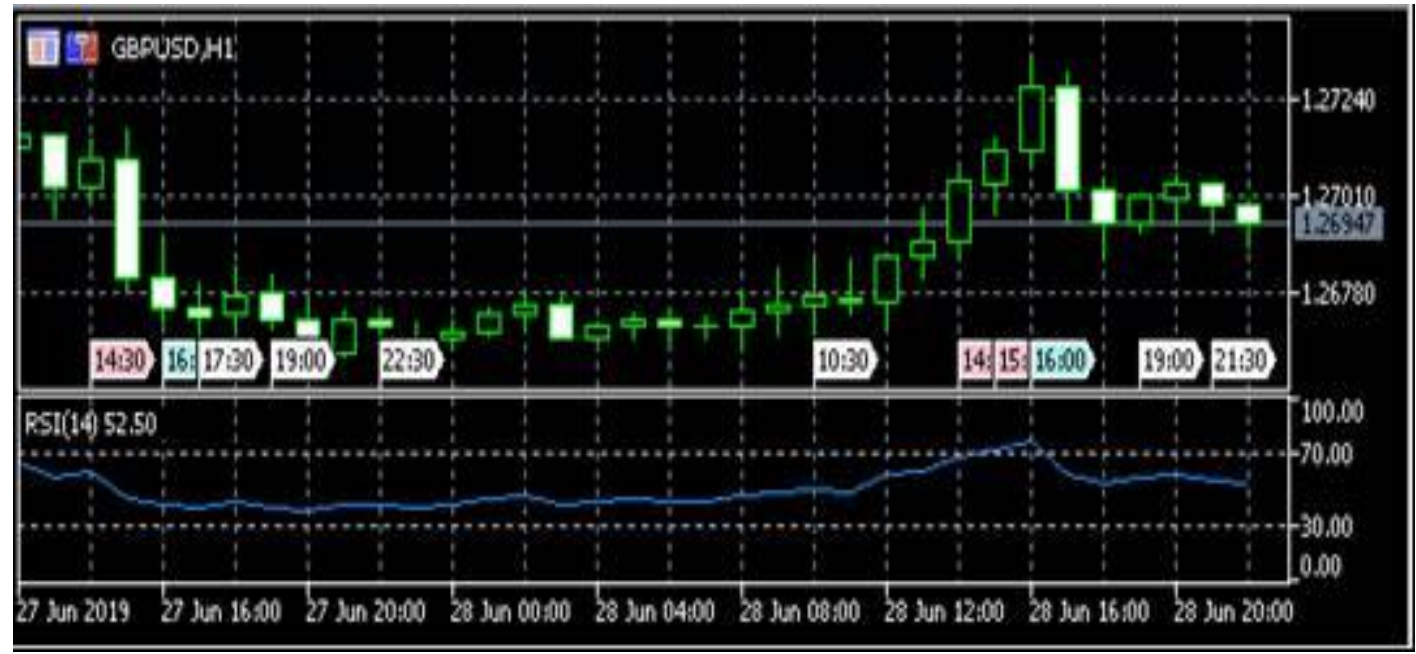

Figure - 2: Relative Strength Index

- It is the best indicator to identify; whether currency is overbought or oversold.

- When overbought currency shows the uptrend in the market the traders buy the currency for long time.

- When the oversold currency shows the downtrend the traders sell the currency for long time

- RSI is limited between 0 to 100 (above 70 overbought, below 20 oversold)

- One should not take the position only by RSI signals. It should be combined with supplement signals sent by other indicators. 


\section{Moving Averages}

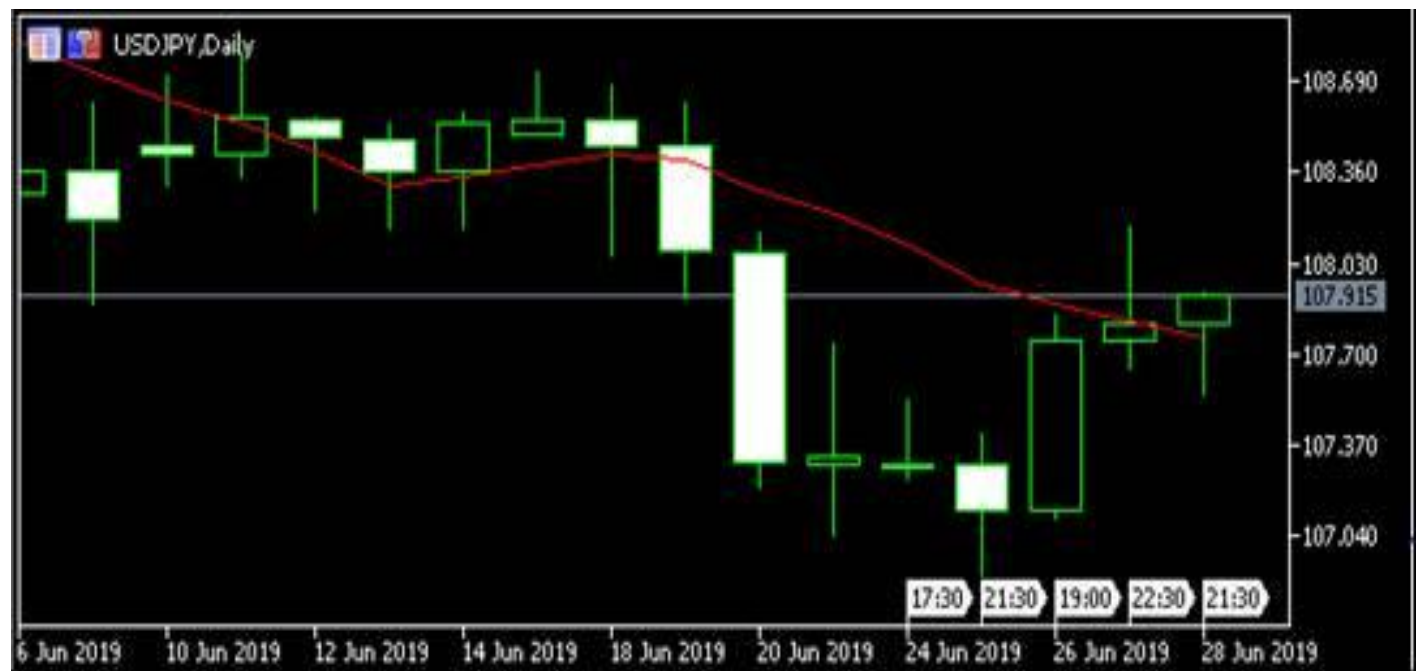

Figure - 3: Moving Averages

This indicator helps to determine the potential direction of the currency. This indicator helps to determine the future prices.

Among traders, the basic and popular moving average Uptrend is observed when the price moves higher and higher above moving average

Below moving average, as price falls down which shows an average is higher than the price.

In the above figure. the bearish trend can be seen which shows the supply is more than the demand.

\section{Bollinger Bands}

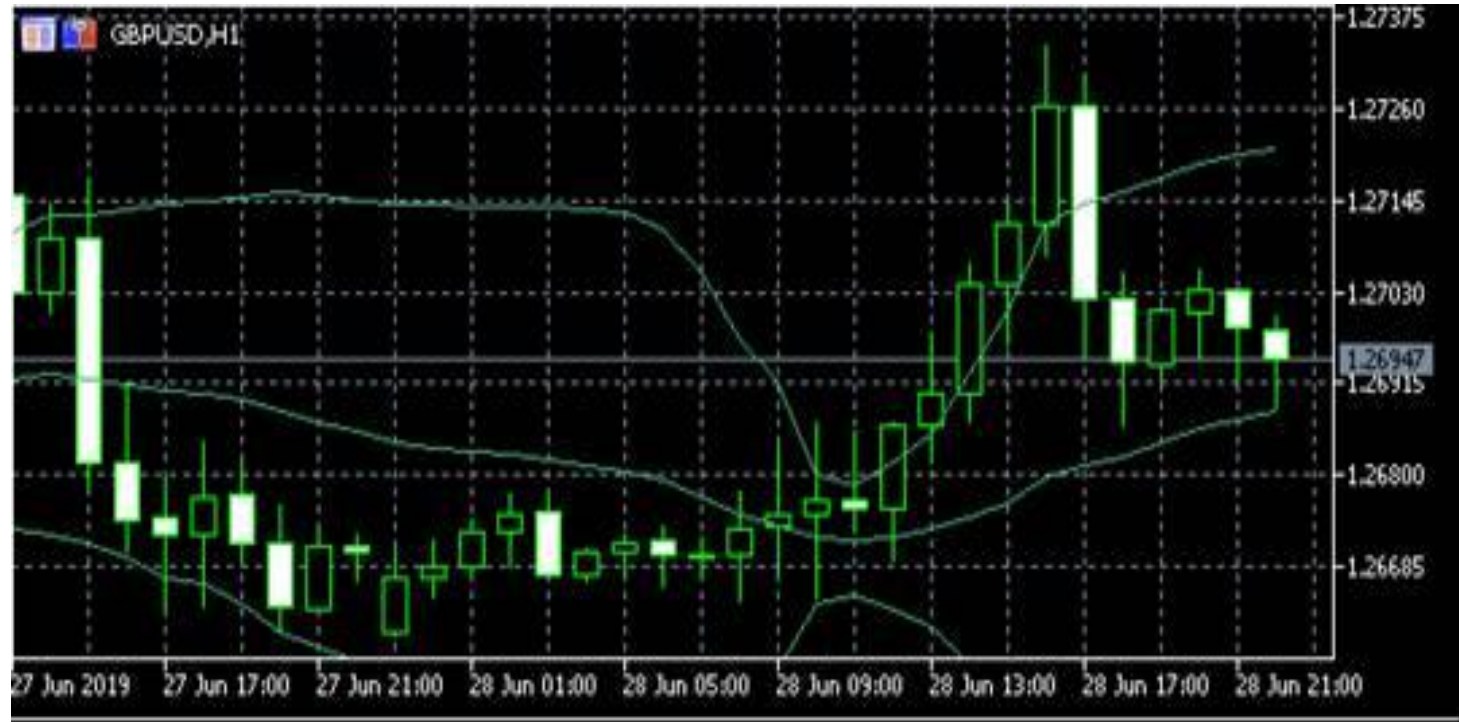

\section{Figure - 4: Bollinger Bands}

- It has three lines they are simple moving average, upper band and lower band.

- This tool tell us whether the market is quite or loud, when the market is quite it contract, when it's loud it expands.

- Bollinger has set 22 rules to follow while trading with these bands.

Table - 1: Summary of Trading Categories

\begin{tabular}{|l|c|c|c|c|c|c|}
\hline & Number of positions & Positions (\%) & $\begin{array}{c}\text { Number of } \\
\text { positive results }\end{array}$ & Positive result (\%) & $\begin{array}{c}\text { Number of } \\
\text { negative result }\end{array}$ & Negative result (\%) \\
\hline Hourly & 52 & 48.14 & 37 & 34.25 & 15 & 13.89 \\
\hline Midday & 28 & 25.93 & 13 & 12.04 & 15 & 13.89 \\
\hline Daily & 28 & 25.93 & 14 & 12.96 & 14 & 12.97 \\
\hline
\end{tabular}

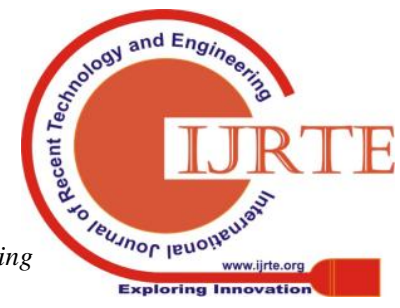




\begin{tabular}{|l|c|c|c|}
\hline Total & 108 & 100 & 64 \\
\hline
\end{tabular}

Interpretation: Table 1 shows 108 executed positions during JUNE $201950 \%$ of all transactions are hourly basis; rest either midday basis or daily basis. Categories Dispersion mentioned below:

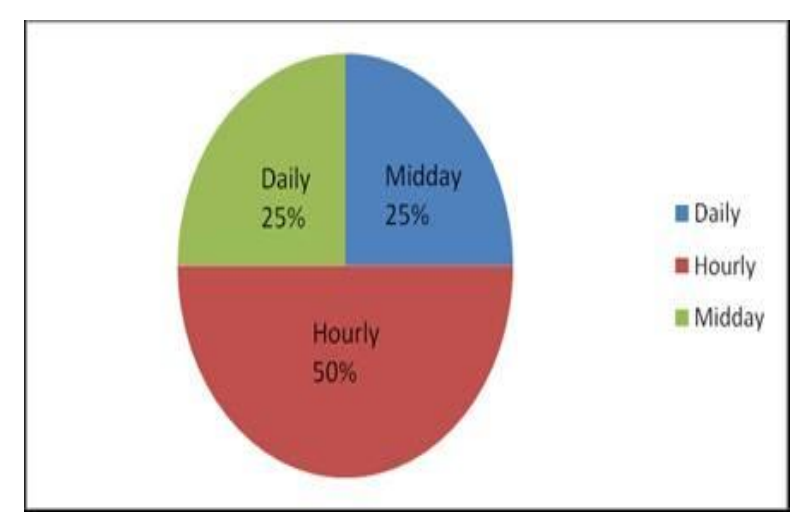

Figure - 5: Dispersion of Categories

Table 1 illustrate, $71 \%$ of hourly positions are executed successfully (37 out of 52), 46\% of midday positions (13 out of 28 ) ended with profit and $50 \%$ of daily positions (14 out of 28) are closed satisfactory.

The result shows, hourly positions success with technical analysis while, daily $\&$ midday stand at second $\&$ third places respectively. Moreover, $57.9 \%$ of total the positive positions belongs to hourly category (37 out of 64) whereas midday category at $20.31 \%$ (13 out of 64 ) \& daily category at $21.79 \%$ (14 out of 64) respectively.

64 transactions out of 108 all transactions are terminated with profit. In percentile $58 \%$ of all transactions hit take profit and closed successfully. The result is depicted below.

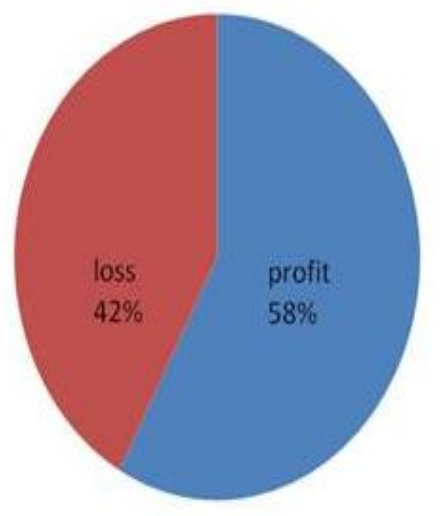

mprofit

\pm loss

Figure - 6: Profit and Loss \%

Table - 2: Summary of Currency Pairs

\begin{tabular}{|l|c|c|c|c|c|c|}
\hline $\begin{array}{c}\text { Currency } \\
\text { pairs }\end{array}$ & $\begin{array}{c}\text { Number } \\
\text { of } \\
\text { positions }\end{array}$ & $\begin{array}{c}\text { Positions } \\
(\%)\end{array}$ & $\begin{array}{c}\text { Number } \\
\text { of } \\
\text { positive } \\
\text { result }\end{array}$ & $\begin{array}{c}\text { Positive } \\
\text { result } \\
(\%)\end{array}$ & $\begin{array}{c}\text { Number } \\
\text { of } \\
\text { negative } \\
\text { result }\end{array}$ & $\begin{array}{c}\text { Negative } \\
\text { result } \\
(\%)\end{array}$ \\
\hline EUR/USD & 25 & 23.15 & 14 & 12.96 & 11 & 10.19 \\
\hline GBP/USD & 35 & 32.40 & 21 & 19.44 & 14 & 12.96 \\
\hline USD/JPY & 20 & 18.52 & 11 & 10.19 & 9 & 8.33 \\
\hline USD/CHF & 28 & 25.93 & 17 & 15.74 & 11 & 10.19 \\
\hline TOTAL & 108 & 100 & 63 & 58.33 & 45 & 41.67 \\
\hline
\end{tabular}

Table 2 illustrate, GBP/USD at $19.44 \%$ out of $58.33 \%$ has most success technical analysis. USD/CHF, EUR/USD and
USD/JPY are placed next with $15.74 \%, 12.96 \%$ \& $10.19 \%$ respectively. Moreover, an even positive position among currency pairs is GBP/USD with $33.33 \%$ (21 out of 63). USD/CHF, EUR/USD and USD/JPY stands next, 26.98\% (17 out of 63 ), $22.22 \%$ (14 out of 63) \& $17.46 \%$ (11 out of 63 ) respectively.

GBP/USD placed first among other currency pairs, reason high economic stability in Great Britain as compare with European countries.

Euro zone is facing problem like debt, challenge for Euro zone countries. Resultant, Euro acts as a sensitive currency and traders are encouraged to trade with more stable currency.

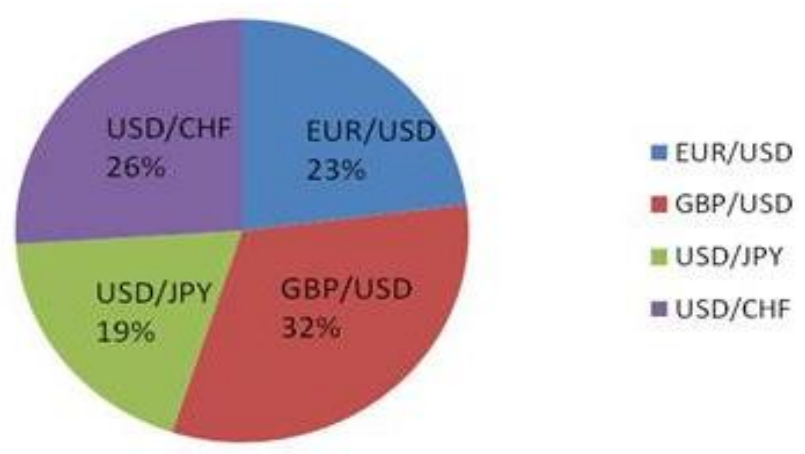

Figure - 7: Dispersion of Currency

Figure 7 represents, $32 \%$ of all the transactions are in GBP/USD whereas $26 \%, 23 \%$ and $19 \%$ transactions are in USD/CHF, EUR/USD \& USD/JPY respectively. In FOREX market, volatility is too high, the probability of volatility and rapid movement become less resultant decrease in the length of position category. For instance, announcing of news (have impact on Forex market) then position lasts for 2 days, will be more probable than a position which is executed in 8 or 10 hours.

\section{CONCLUSION}

2018, Bank for international settlements (BIS) global results shows that trading in foreign exchange markets averaged per day is $\$ 5.3$ trillion. Among four major currency pairs of FOREX market i.e. EUR/USD, GBP/USD USD/JPY \& USD/CHF. GBP/USD pair, most preferred trader's currency pair due to stability and reliability on Great Britain economy then stands USD/CHF, EUR/USD and USD/JPY respectively. Due to market volatility, hourly category is more sensation technically moreover probability of volatility and rapid movement become less, decrease in the length of position category.

\section{REFERENCES}

1. Archer, M. D. (2012). Getting Started in Currency Trading, Companion Website:

2. Winning in Today's Market (Vol. 95) : John Wiley \& Sons, 2012.

3. Bickford, J. L. (2008). Forex shockwave analysis. New York: Mc Graw-Hill Professional, Inc., U.S.A. 
4. Booker, R. (2006). The Currency Trader"s Handbook: Strategies for Forex Success, LULU.

5. Bulkowski, T. N. (2005). Encyclopedia of Chart Patterns (Vol. 225). John Wiley \& Sons, Inc., U.S.A.

6. Chen, J. (2009). Essentials of Foreign Exchange Trading (Essentials Series), John Wiley \& Sons, Inc., U.S.A.

7. Duddella, Suri (2008). Trade chart patterns like the pros : specific trading techniques. [S.1.]: Surinotes.com. ISBN 978-1-60402-721-1.

8. MetatTrader 4 [Computer Program]. Version: 4.00 Build 509. England: FXPRO Financial Services LTD; 2013.

9. Miyazaki, H. (2007). Between arbitrage and speculation: an economy of belief and doubt, Economy and Society, 36:3, 396-415, DOI: $10.1080 / 03085140701428365$

\section{AUTHORS PROFILE}

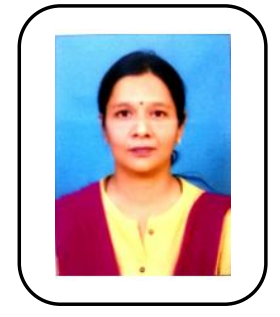

Dr. Ritu Kothiwal, presently working as Controller of Assessment \& Evaluation, VISHWA VISHWANI INSTITUTE OF SYSTEMS \& MANANGEMENT, Hyderabad She is Post Graduate in Commerce and Business Management \& done her $\mathrm{PhD}$ from $\mathrm{Ch}$. Charan Singh University, Meerut (U.P.) In her 20 years of both Industry \& Academic experiences, participated, presented and published more than 25 research papers in national and international seminars $\&$ conferences. Her areas of research are Financial Markets, Banking \& Insurance, Direct Taxation and Investment Banking, acting as PhD guide of Mewar University Rajasthan.

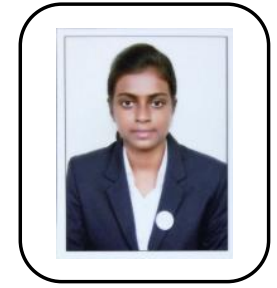

Abinaya Rajiyan , B.Com, PGDM (Pursuing), creator of strong work ethic pursuing PGDM in Finance and Business Analysis from VISHWA VISHWANI INSTITUTE OF SYSTEMS \& MANANGEMENT, Hyderabad . Did internship in JMarathon Advisory Pvt. Ltd. and achieve certification of NISM VIII Equity Derivative Module. Her area of interest, Financial market, Forex market and Financial Analysis. 